\title{
EVENTRATION OF THE DIAPHRAGM
}

\author{
WITH REPORT OF A CASE OF RIGHT-SIDED EVENTRATION * \\ STANHOPE BAYNE-JONES, M.D. \\ BALTIMORE, MD.
}

Among the lesions of the diaphragm, none has passed into the literature under more synonyms than the condition commonly called "eventration." Since 1849, when Cruveilhier introduced his conception of the disease under this term, the names: "dilatation," "relaxation" (Wieting), "insufficiency" (Franck), "high position," "elevation" (Griffin), have been used to designate a pathological state of the diaphragm, characterized by a general expansion of one half of the organ, allowing the abdominal viscera to be displaced upward into the thoracic cavity. The diaphragm is greatly thinned as well as distended, but its three layers remain intact, and there is no solution of its continuity. In this essential respect, the condition is different from hernia of the diaphragm, which, whether true or false, depending on the presence or absence of a hernial sac, consists of a localized opening in the sheet of the diaphragm, through which the abdominal viscera pass into the thoracic cavity. All of the terms mentioned are partially descriptive, though none is satisfactory. While the commonest of them, "eventration," is a gross misnomer, since it suggests the displacement of the viscera out of the abdomen, it has received by custom a connotation which is specific for this condition of the diaphragm. The other terms are so ambiguous that if any one of them were accepted, it would yet have to acquire a long usage to gain the special meaning needed in this connection. As its multiplicity of names suggests, eventration is one of the rare lesions of the diaphragm. The latest statistics of its frequency as compared with other types of hernia of the diaphragm, published by Eppinger in 1911, show the following incidence :

TABLE 1.-Frequency of HFrnia and Eventration

$\begin{array}{ccc}\text { Type of Diaphragmatic Hernia } & \text { Right Side } & \text { Left Side } \\ \text { Hernia vera } \ldots \ldots \ldots \ldots \ldots \ldots \ldots \ldots & 21 & 53 \\ \text { Hernia spuria } \ldots \ldots \ldots \ldots \ldots \ldots \ldots & 34 & 527 \\ \text { Eventratio } \ldots \ldots \ldots \ldots \ldots \ldots \ldots \ldots & 2 & 15\end{array}$

Total cases of hernia, 635. Total cases of eventration, 17. Ratio of eventration to hernia, 1 to 37 .

* Submitted for publication Oct. 11, 1915.

* From the Medical Clinic of The Johns Hopkins Hospital. 
Since the compilation of these figures, many cases of hernia have been reported, and the number of cases of eventration has risen to forty-five. But the relative incidence of these lesions has probably remained so constant that this proportion is still a fair index of the rarity of the condition. This table is further interesting in showing the relative infrequency of hernia and eventration of the right side of the diaphragm. The case to be reported in this paper is thus seen to be the third example of right-sided eventration.

Thirty-one cases of eventration of the diaphragm were collected and summarized by Bergmann in 1913. A review of the literature, however, reveals several reports omitted by him and, in addition, several published since his article. The following is a tabulation of forty-five case-reports-forty-four gathered from the literature and one new case, reported in this paper.

\section{REPORT OF CASE}

Diagnosis.-Eventration of the right side of the diaphragm. Congenital malformation of the mesentery, with mesenteric hernia. Chronic intestinal obstruction.

History.-J. B., a white male, aged 52, was admitted to the Medical Clinic of The Johns Hopkins Hospital, November 16, 1914. General No. 99055. Complaint, "Pain in the upper right side of the stomach."

The patient came from healthy stock and was the father of five normal children. In general his health had been robust, except for typhoid fever, complicated by pneumonia, when he was 19 years old, he had not been incapacitated by any acute infectious disease. In his occupation as a sailor, chiefly around harbors, he had led an active life. He was not addicted to the use of alcohol or tobacco.

Throughout his life a "sensitiveness of the stomach" had necessitated a moderate degree of care in the selection of his diet. In 1909, five years ago, he began to have "indigestion," associated with constipation and pains in the upper right quadrant of the abdomen. This pain was "knife-like," extending from the midline to the axilla, above the umbilicus and below the costal margin. The pain could be relieved by pressure on that side of the abdomen. The pain recurred at irregular intervals, and sometimes was accompanied by nausea and vomiting. He was never jaundiced and did not have tarry stools. He had not been dyspneic. Lately the pain has recurred more frequently and has radiated into the right shoulder. This has incapacitated the patient, and he has lost 17 pounds in the past five months.

Physical Examination.-The patient, a large-framed, well nourished man, is neither dyspneic, cyanotic, nor jaundiced. The general examination is unimportant, except as regards the thorax and abdomen.

Thorax: The thorax is deep, with a wide costal angle. Both sides expand equally; by measurement, the right from 45 to $47 \mathrm{~cm}$., the left from 45 to $46 \mathrm{~cm}$. On the left side there are no abnormal signs. On the right side, vocal fremitus is not palpable in the axilla. The percussion note at three successive levels changes from resonance to flatness and to tympany. The note is resonant over the upper right front and back. At the third rib it becomes dull, and below this it is flat to the level of the fifth rib. From the fifth rib downward the note has a dull tympanitic quality, until the full abdominal tympany is reached. At the base posteriorly the lower border of pulmonary resonance is $10 \mathrm{~cm}$. higher on the right than on the left, and only slight descent of this is percepti- 
ble on the right. A tympanitic area occupies the usually dull region of the lower ribs in the back. Litten's sign is absent in the right axilla. On auscultation, enfeebled breath sounds are heard over the upper portions of the right lung. These sounds gradually diminish until below the level of the fourth rib the sounds of breathing and of voice are inaudible. There is no egophony.

Abdomen: The abdomen is not distended, but on the right side the muscles are resistant. Varying irregular masses are palpable in the right upper quadrant, in a region which is painful when pressed on. The edge of the liver cannot be felt, and the area of hepatic dulness seems to end at the level of the fifth rib. In the region of the lower ribs behind, the percussion note is tympanitic, as it is over the front of the right upper quadrant. On the left side there is a small inguinal hernia. Inflation of the colon, by pumping air into the rectum, causes the abdomen to become distended, while the level of tympany on the right side is advanced upward an interspace. This distention causes pain like the distress which characterizes the patient's illness.

Results of Special Examinations.-Gastric Analysis: Free HCl, 34; total acidity, 72.

Feces normal. Urine normai.

Wassermann reaction negative. R. B. C., 4,792,000; Hb., 72 per cent.; W. B. C., 7,440. Widal test negative. Conjunctival tuberculin test, 5 per cent., slightly positive.

Heart: The heart is not enlarged or displaced. The electrocardiogram (Film H-09) shows "normal rhythm, with no abnormal complexes. Conduction time 0.18 second. There is a progressive decrease in the size of the R-wave. Normal electrocardiogram."

As the result of these examinations, Dr. Janeway excluded thickened pleura, which among other conditions had been considered the likely explanation of the abnormal physical signs over the right side of the chest, and made the diagnosis of eventration of the right side of the diaphragm. This conception was strengthened by the following radiographic studies, and when confirmed at subsequent operation, proved to be the first instance of the intra vitam diagnosis of this condition.

Roentgenologic Findings (Dr. Baetjer and Dr. Waters) :

Thorax: (Plate 26278. Fig. 1). The lung shadows are normal. The dome of the right diaphragm is very high, reaching approximately the level of the third rib in front. It is normal in shape.

The fuoroscopic examination shows on the right side a high diaphragm, which is normal in shape. On deep respiration the movement of this side is paradoxical; it moves upward during inspiration and downward during expiration. The left side of the diaphragm moves freely in long sweeps downward during inspiration. The heart appears to be normally placed. The stomach is in a high position with its pylorus under the right costal margin. The colon, filled with bismuth, shows double and complicated kinking on the right side.

Large Intestine: (Plate 26196. Fig. 2). This shows the descending colon and the splenic flexure in their normal situations. The transverse colon is prolapsed, and in the right upper quadrant it is looped and doubled on itself. On the right side of the plate there is no shadow to indicate the position of the ascending colon.

These evidences of abdominal disease confirmed the impression that a chronic inflammatory condition, possibly cholecystitis, was present in the right upper quadrant. Because of this, an exploratory laparotomy was performed by Dr. J. M. T. Finney, Dec. 4, 1914. The following is the summary of the note of operation (see Fig. 3) :

Neither the liver nor the gallbladder is visible through the right rectus incision. The gallbladder is found roughly a hand's breadth above the costal margin, at the level of the sixth rib. It is normal. The liver, slanting downward and to the left, looks normal, but is situated high up under the ribs. 
TABLE 2,-SuMMARY OF CASES-

\begin{tabular}{|c|c|c|c|c|c|c|}
\hline $\begin{array}{l}\text { Case! } \\
\text { No. }\end{array}$ & Year & Author & $\operatorname{Sex}^{*}$ & Age & $\begin{array}{c}\text { Side } \\
\text { Affected }\end{array}$ & Ohief Clinical Findings \\
\hline 1 & 1784 & Pyl............. & $\sigma^{\circ}$ & $1 \mathrm{da}$. & Left & Death soon after birth. Cyanosis.............. \\
\hline 2 & 1790 & Petit........... & $\sigma^{*}$ & ad. & Left & "Asthma, after eating"...................... \\
\hline 3 & 1819 & Meckel.......... & $\sigma^{*}$ & fet. & Left & (n, \\
\hline 4 & 1829 & Laennec......... & $\sigma^{\circ}$ & ad. & Left & .................. \\
\hline 5 & 1837 & Froriep......... & q & 19 & Left & Dyspnea and digestive disorders for 14 years... \\
\hline 6 & 1852 & Lawrence........ & $\sigma^{\pi}$ & 33 & Left & Practically no symptoms.............. \\
\hline 7 & 1867 & Marsh........... & $\delta$ & 33 & Left & 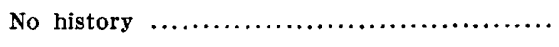 \\
\hline 8 & 1882 & Thoma.......... & $\sigma^{\circ}$ & 75 & Left & No history $\ldots \ldots \ldots$ \\
\hline 9 & 1894 & Tennant........ & $\sigma^{\circ}$ & 60 & Left & 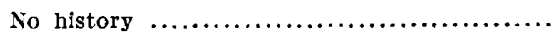 \\
\hline 10 & 1900 & Crispino......... & $\varsubsetneqq$ & 55 & Left & Gastro-intestinal disorders. Fractured arm.... \\
\hline 11 & 1901 & Struppler........ & $\sigma^{*}$ & 26 & Left & $\begin{array}{l}\text { Life-long cough. Dyspnea after trauma. Physi- } \\
\text { cal signs of hernia. Roentgen-ray signs of } \\
\text { eventration }\end{array}$ \\
\hline 12 & 1901 & Neisser.......... & $\sigma^{\prime}$ & 42 & Left & $\begin{array}{l}\text { Bronchiectasis. Signs of intestines in left } \\
\text { chest. Roentgen ray of eventration }\end{array}$ \\
\hline 13 & 1902 & Doering.......... & $\sigma^{*}$ & 60 & Left & Dyspnea many years. Signs of hernia......... \\
\hline 14 & 1902. & Fraenkel......... & $\delta$ & 49 & Left & $\begin{array}{l}\text { Dyspnea and hemoptysis several years. Signs } \\
\text { of hernia by phys. exam. and Roentgen ray }\end{array}$ \\
\hline 15 & 1905 & Hildebrand and & $\sigma^{\pi}$ & 39 & Left & $\begin{array}{l}\text { Inearceration symptoms for many years. } \\
\text { Famous case of "Sch." }\end{array}$ \\
\hline 16 & 1905 & Sailer and Rhein & $\sigma^{3}$ & 20 & Left & Signs of subdiaphragmatic gas abscess........ \\
\hline 17 & 1906 & Wieting.......... & $\sigma$ & 50 & Right & Symptoms of gallstones. Operation............. \\
\hline 18 & 1907 & Kienböck........ & $\sigma$ & 54 & Left & $\begin{array}{l}\text { Trauma to right slde years previously. Signe } \\
\text { of hernia. Roentgen ray of eventration }\end{array}$ \\
\hline 19 & 1007 & Herz............ & $\sigma$ & 36 & Left & Cough, Typical signs of eventration............ \\
\hline 20 & 1908 & Arnsperger...... & q & 20 & Left & No symptoms. All signs of eventration...... \\
\hline 21 & 1909 & Königer.......... & $\stackrel{q}{q}$ & 27 & Left & $\begin{array}{l}\text { Dyspnea and pain several years. The usual } \\
\text { signs of eventration }\end{array}$ \\
\hline 22 & 1910 & $\begin{array}{l}\text { Otten and Schef. } \\
\text { old }\end{array}$ & $\sigma^{\pi}$ & 68 & Left & Paradoxical dysphagia. Usual signs........... \\
\hline 24 & 1910 & Beltz............ & $q$ & 34 & Left & $\begin{array}{l}\text { Dyspnea, pain in left side, gastric disorders. } \\
\text { Typical findings } \\
\text { No history } \ldots \ldots \ldots \ldots \ldots \ldots \ldots \ldots \ldots \ldots \ldots \ldots \ldots \ldots \ldots \ldots\end{array}$ \\
\hline 25 & 1911 & Scholz............ & $\sigma$ & 1 & Left & Slight dyspnea and indigestion................ \\
\hline 26 & 1911 & Eppinger.......... & $\sigma^{*}$ & 35 & Rlght & $\begin{array}{l}\text { Typical signs of eventration. Case not seen } \\
\text { in life }\end{array}$ \\
\hline 27 & 1911 & Franck........... & $\sigma$ & 73 & Left & $\begin{array}{l}\text { Right hemiplegia } 12 \text { jears. Ohronic constipa- } \\
\text { tion. Typical eventration }\end{array}$ \\
\hline 28 & 1911 & Appel........... & $\sigma$ & 60 & Left & Dyspnea 2 years. Typical eventration.......... \\
\hline 29 & 1911 & Becker.......... & $\sigma^{*}$ & 25 & Left & Life-long gastric discomfort. Typical......... \\
\hline 30 & 1912 & Scheidemandel., & $\sigma$ & 21. & Left & Pain between shoulders. Usual signs.......... \\
\hline 31 & 1912 & Schejdemandel.. & $\sigma^{\pi}$ & 55 & Left & Cough 36 years. Typical signs.................. \\
\hline 32 & 1912 & Malkow.......... & $\sigma^{*}$ & 45 & Left & Typical signs, according to Bergmann........... \\
\hline 33 & 1913 & Bergmann....... & $\sigma^{7}$ & 60 & Left & Gradual onset of dyspnea. Typical............ \\
\hline 34 & 1913 & Kayser........... & $q$ & 28 & Left & No symptoms. Typical fledings................. \\
\hline 35 & 1913 & Haase........... & child & $3 \mathrm{mos}$. & Left & Cough and dyspnea. Typical flndings........... \\
\hline 36 & 1913 & Reuss............ & $0^{*}$ & 46 & Left & Injured left side. Typical findings.............. \\
\hline 37 & 1913 & Baetge........... & $\sigma^{\prime \prime}$ & 64 & Left & $\begin{array}{l}\text { Dyspnea and palpitation many years. Typical } \\
\text { signs of eventration }\end{array}$ \\
\hline 38 & 1913 & Baetge.......... & $\sigma^{*}$ & 28 & Left & Gastro-intestinal disorders. Typical eventration \\
\hline 39 & 1913 & Baetge........... & $\sigma^{*}$ & 41 & Left & $\begin{array}{l}\text { Dyspnea and stomach trouble since childhood. } \\
\text { Typical signs }\end{array}$ \\
\hline 40 & 1913 & Motzfeldt....... & $q$ & 41 & Left & Practically same as Case $39 \ldots \ldots \ldots \ldots \ldots \ldots$ \\
\hline 41 & 1913 & Krause........... & $\sigma^{\pi}$ & 42 & Left & Gastric disorders. Typical signs............... \\
\hline 42 & 1913 & Krause........... & q & 36 & Left & After pregnaney. Typical signs................ \\
\hline 43 & 1914 & $\begin{array}{l}\text { M a g ges and } \\
\text { Wessler }\end{array}$ & 8 & 35 & Left & $\begin{array}{l}\text { Gastric crises, dyspnea, cyanosis. Typical signs } \\
\text { of eventration }\end{array}$ \\
\hline 44 & 1914 & Fischer.......... & $\sigma^{*}$ & 30 & Left & $\begin{array}{l}\text { Found at conclusion of typhoid fever compli- } \\
\text { cated by pneumonia }\end{array}$ \\
\hline $4 \check{5}$ & 1915 & Author's case... & $\sigma$ & 52 & Right & $\begin{array}{l}\text { Painful febrile periods suggesting gallbladder } \\
\text { disease. Tympany over lower right chest. } \\
\text { Right diaphragm by Roentgen ray at third rib }\end{array}$ \\
\hline
\end{tabular}

${ }^{*} d=$ male; $q=$ female. 


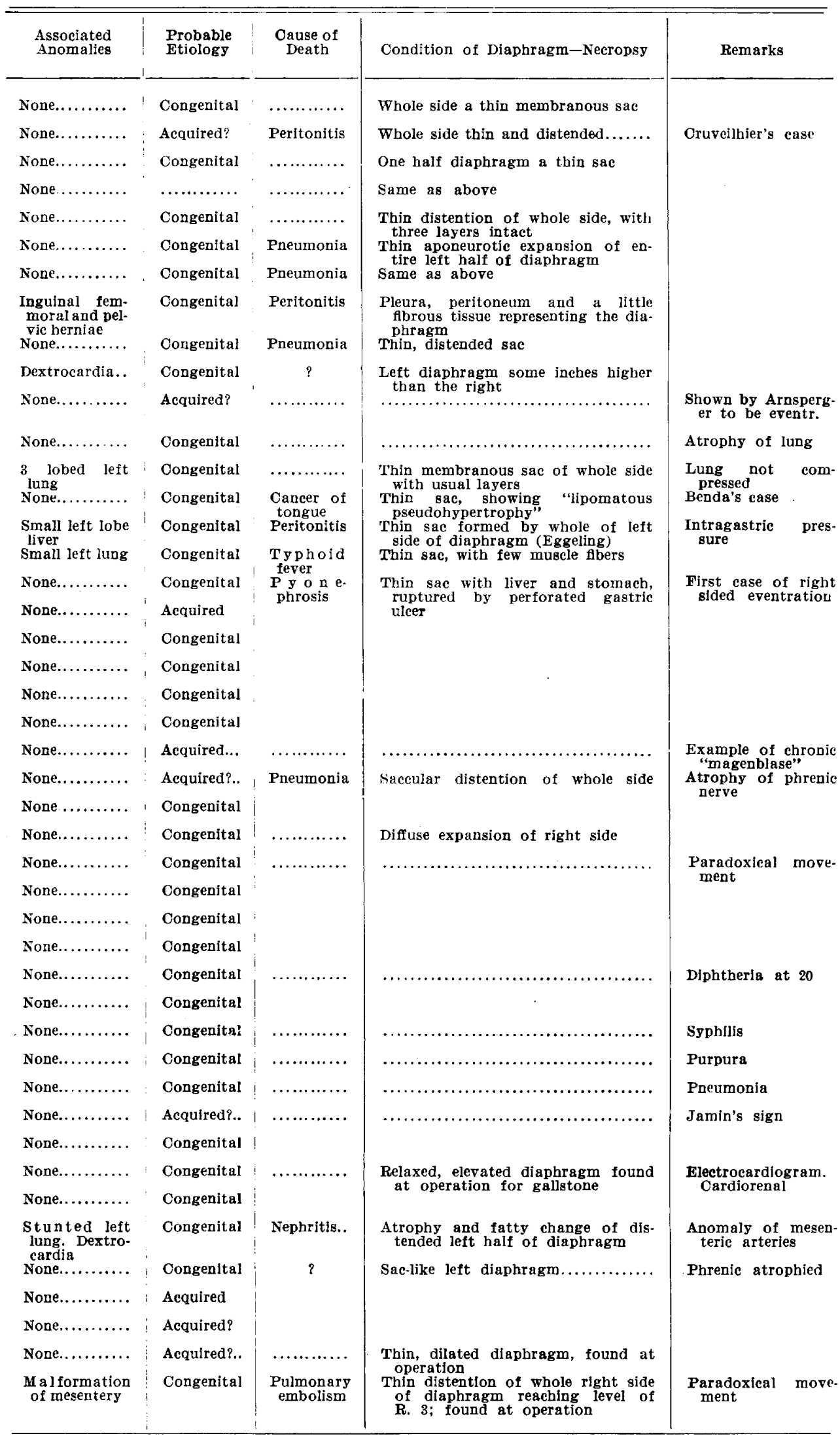


The hand passed over the dome of the liver touches the third rib in front, and by slight pressure the second interspace can be reached. The diaphragm is thin, but otherwise normal. It can be felt to cover the liver smoothly, and has no localized bulging or solution of continuity.

The stomach is normal, but has its pyloric end high under the right costal margin. The transverse colon is redundant and together with a loop of small intestine passes through a hernia in the root of the mesentery. In this anomalous formation of the mesentery there are large dilated veins and an aberrant artery. The cecum is high under the costal margin on the right side.

From these notes and from a sketch made at the operation, Mr. Brödel elaborated the drawing reproduced as Figure 3. This shows clearly the anatomical relationships of the high diaphragm and the displaced viscera, and at a glance, offers the explanation of both the gastro-intestinal symptoms and also the physical signs over the chest and abdomen.

The patient progressed well for ten days after the operation, when suddenly he became dyspneic, spat blood, and died after a few minutes, with symptoms of pulmonary embolism. As a necropsy was not permitted, no further examination of the diaphragm was possible.

\section{DIFFERENTIAL DIAGNOSIS}

Previous discussions of the differential diagnosis between eventration and conditions presenting similar signs have been limited to the consideration of left-sided lesions. The case just described directs emphasis on the diseases of the right thoracico-abdominal section of the body. At the same time, however, completeness and clarity require a review of the findings in the left-sided cases.

In the case described herein, the abdominal symptoms were the urgent cause of the patient's coming to the hospital. The intermittent periods of pain in the right upper quadrant, associated with vomiting and fever, made it seem likely that there was some chronic inflammatory disease in that region. Among the diagnoses considered were duodenal ulcer, with perforation and a localized gas abscess beneath the right lobe of the liver, kinking of the transverse colon, producing intestinal obstruction, and cholecystitis. This last diagnosis was considered the most probable, and was the point determining the operation on the patient. The mesenteric hernia, found at operation, must have produced frequent mild incarcerations of the intestines passing through it. This explanation is sufficient to permit the dismissal here of this phase of the subject.

In the absence of signs of fluid, thickened pleura over the lower part of the right chest was thought at first to be the cause of the dulness on percussion, the diminution of the breath- and voice-sounds, the absence of fremitus and of Litten's sign in the right axilla. However, the exact location of the flatness and of the complete loss of vocal sounds over a region from the third to the fifth ribs, lying between normal lung resonance above and a curious area of tympany below, made it seem more likely that this region was occupied by the liver. Inflation of the colon displaced this area of dulness upward 
and increased the tympanitic region below, as would occur with a semimovable organ like the liver lying in the relaxed and elevated dome of the diaphragm, but which would not occur in thickened pleura. The most closely allied condition, which would give some of these signs, is hernia of the right side of the diaphragm. Of this lesion, for comparison, we have only one case-perhaps the only case diagnosed during the life of the patient-namely, that reported by Dietlen and Knierim. In their case, the stomach and some coils of intestine passing through the diaphragm into the thoracic cavity, lay above the liver. Here, the area of tympany across the chest, lay between normal lung resonance and the area of hepatic dulness. Changes in the position of the patient and the ingestion of fluids and gases somewhat modified the sounds elicited by percussion and auscultation over the tympanitic area, giving almost the reverse order of the two lower strata of physical signs noted in our case of eventration of the òiaphragm.

In our case, the radiographic and fluoroscopic examinations confirmed the clinical impression of eventration of the diaphragm. The left side appeared to be normal, while the right showed a smooth shadow arching upward across the thorax to the level of the third rib (Fig. 1). Above this shadow, normal pulmonary shadows were visible, while below it, the stomach and intestines, when filled with bismuth, could be clearly seen. This contrasts sharply with the roentgenograms in hernia of the right side of the diaphragm. In Dietlen's and Kneirim's case, a bright area was seen between the lung shadows and the black hepatic region. When bismuth paste was administered, the peristaltic shadows of the stomach and small intestine obliterated this bright idea (Fig. 4). The movement of the diaphragm in these two cases is so contradictory that it indicates the doubtful value of this sign in the differentiation of eventration from hernia of either the right or the left side of the diaphragm. In 1898, Kienböck observed paradoxical movement of the diaphragm by the fluoroscopic screen. This form of motion is characterized by inspiratory elevation and expiratory descent of the affected side of the diaphragm. Though it is found in numerous conditions, such as pleurisy with effusion, and pyopneumothorax, it was observed in a case of hernia of the left side of the diaphragm, and seized on as one of the definite radioscopic signs of this condition. In our case of eventration, the movement of the thin distended side of the diaphragm was paradoxical in character, while in the case of hernia, the movement of the upper borders of the diaphragmatic shadows was normal, descending with inspiration and rising with expiration. Before this, however, Lotze's case had proved that the differential diagnosis between hernia and eventration cannot 
be made with absolute certainty by means of the Roentgen ray. He cescribed what seemed to be a typical example of eventration of the left side of the diaphragm, in which the respiratory excursions of the diaphragm were normal, though diminished. Several years later, when Risel performed the autopsy on this patient, he found an old hernia of the left side of the diaphragm, with the rest of the organ practically normal.

A most decisive differential fact may be gained from the study of the intragastric pressure, according to the method of Marey and

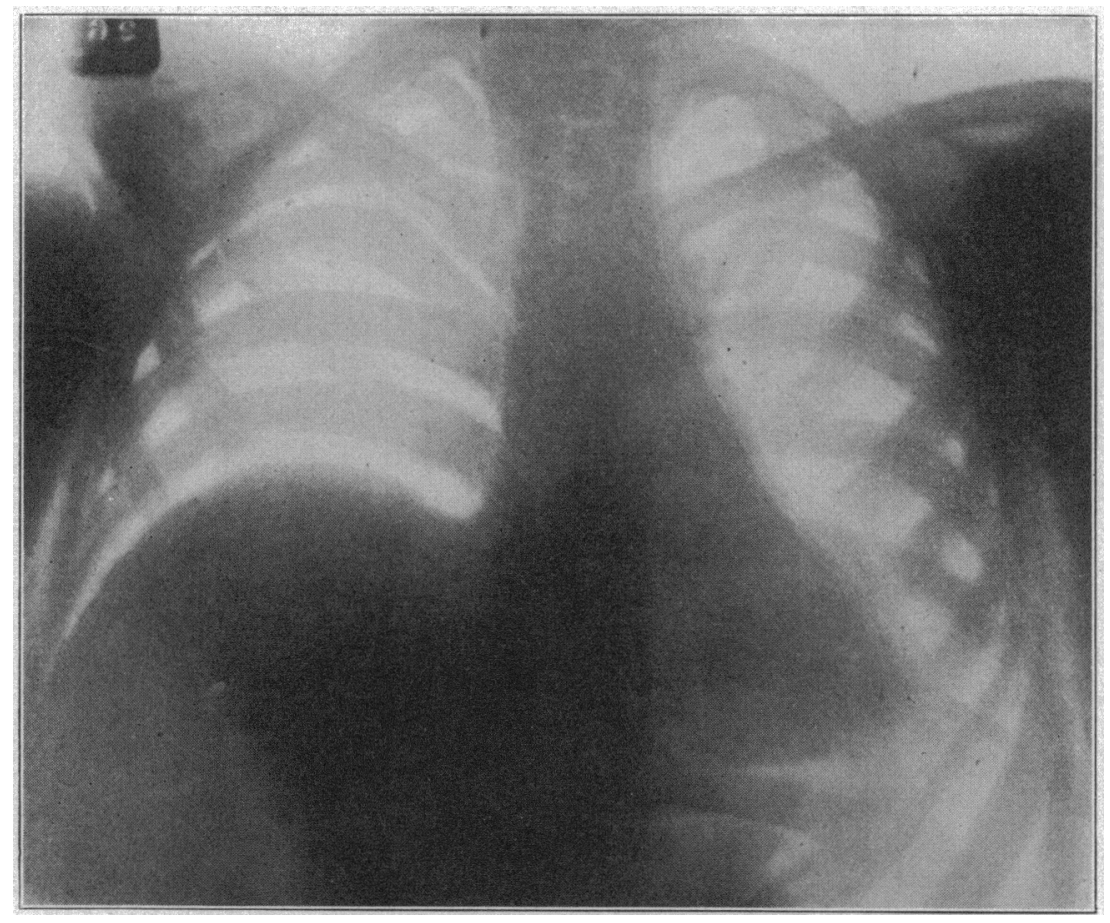

Fig. 1 (Roentgen-Ray Plate 26278).-Thorax: showing the dome of the left diaphragm, normal in outline, arching to the level of the third rib in front. Above this are normal lung shadows, and below the hepatic shadow is a bright area occupied by the intestines displaced upward. On the left the heart and diaphragm are in normal position.

Sichlippe. By the application of this method, Hildebrand and Hess correctly diagnosed as eventration of the left side of the diaphragm, the famous case of "Sch.," which, for a period of twelve years, was studied in many clinics as an example of hernia. By suitable instruments, a record is made of the respiratory phases of the pressure within the stomach, to determine whether the organ is situated within the abdominal or thoracic cavity. If the stomach is in its usual place, 
the pressure within it rises during inspiration and falls during expiration, synchronously with the intra-abdominal pressure. If, however, the stomach lies in the thoracic cavity, the curves are reversed; the pressure falls during inspiration and rises during expiration, synchronously with the changes in the intrathoracic pressure. This investigatuon was not made in our case, but Dietlen and Knierim found that

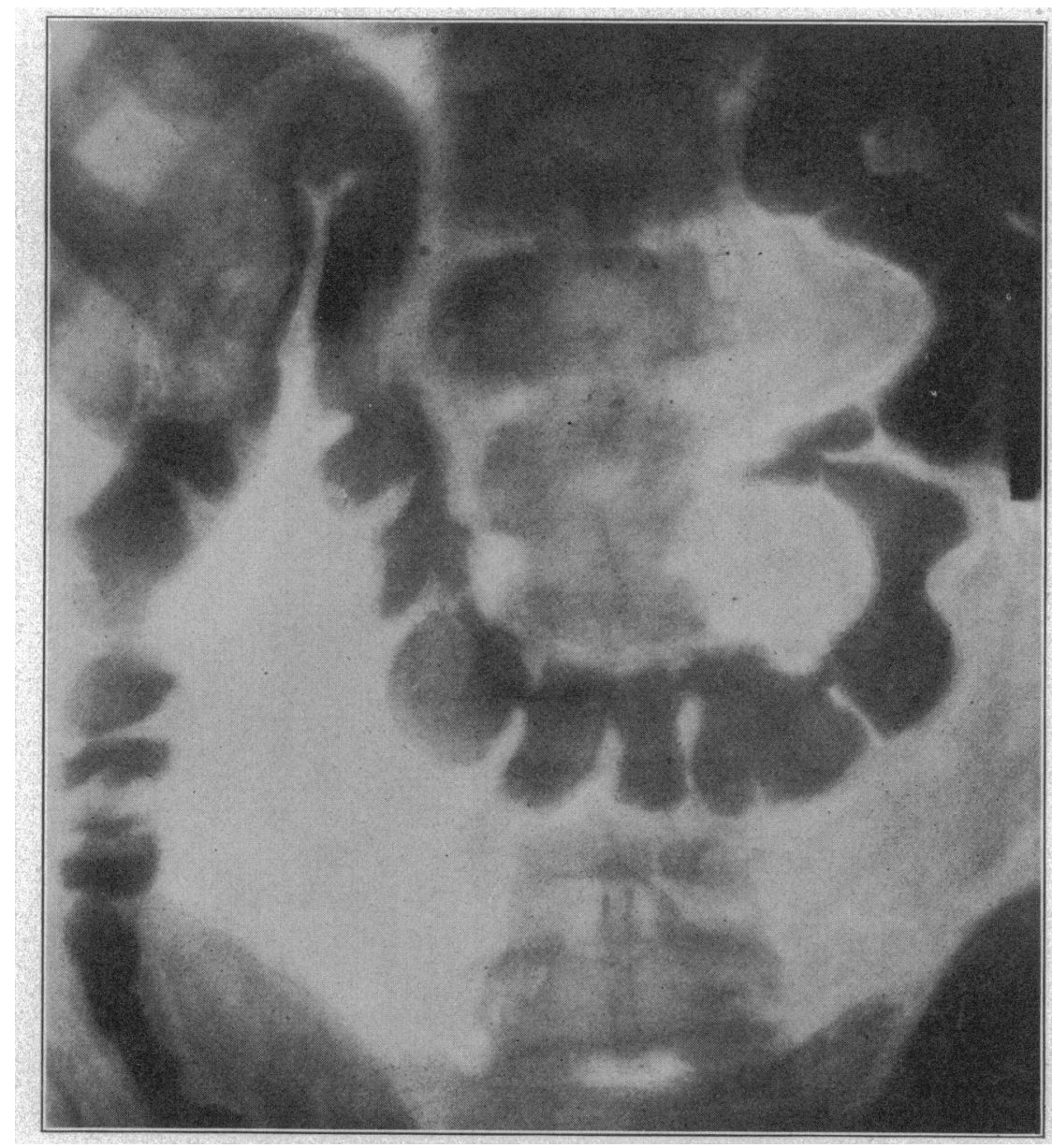

Fig. 2 (Roentgen-Ray Plate 26196).-Bismuth in the large intestine. This slows the prolapse and kinking of the transverse colon in the upper right cluaklant, with absence of shadow of the ascending colon on the right side.

the intragastric pressure varied according to the intrathoracic formula in their case of hernia.

When, in Table 2, it is stated that a case exhibited typical physical the following are implied: A normally formed thorax, with somewhat and radiographic signs of eventration of the left side of the diaphragm, 
diminished expansion on the left side; normal physical signs on the right side, except for the usual evidence of displacement of the heart to that side; normal pulmonary resonance and vesicular breath-sounds over the upper half of the left side, but below the level of the fourth rib, in front and behind, a tympanitic note, absence of voice and breath-sounds, absence of vocal fremitus, and absence of Litten's sign in the left axilla; in place of respiratory murmur, splashing and netallic sounds elicitable over the lower left chest, with great variation in these according to the degree of fulness of the stomach. These physical signs may be given wholly or in part by (1) hydropneumothorax or pyopneumothorax, (2) subphrenic gas abscess, (3) large cavity in the lower lobe of the left lung, (4) paralysis of the diaphragm, and (5) hernia of the diaphragm. The differentiation by simple physical examination between these conditions is almost impossible. Many of the cases of eventration have been explored with the aspirating needle under the supposition of pyopneumothorax (Sailer and Rhein). While the signs here may be similar, the history and general condition of the patient with eventration are different from those features of the other diseases. In eventration, there is not likely to be the sudden onset, great dyspnea and fever that characterizes pyopneumothorax. In subphrenic gas abscess, such as occurs with a walled-off perforation of an ulcer of the stomach, Litten's sign may be still visible in the axilla, while the general condition indicates an acute septic state rarely present in eventration. But in these states, as in hernia, the greatest assistance in diagnosis is derived from investigation by the Roentgen ray.

These differential radiologic findings have been summed up by Becker in a beautifully illustrated paper, as follows:

In both hernia and eventration a delicate bow-shaped line may be seen arching upward across the left side of the chest. In hernia, the contour of this line is irregular, partly distinct, partly blurred; it usually shows a paradoxical respiratory movement; when the stomach and intestines are filled with bismuth, extreme derangement of the line is caused by the new shadows, and when the stomach is inflated with $\mathrm{CO}_{2}$ the line shows practically unlimited extension upward, along with obvious displacement of the stomach, and the lung shadows can be seen through the bright area of the inflated stomach. In eventration, the contour of the line is that of a smooth, sharply defined bowshaped shadow, with a bright area below and lung-shadows above; the movement is usually normal but diminished; when the stomach and intestines are filled with bismuth, the new shadows take a restricted dome-like position, and when the stomach is inflated there is only a smooth distention, limited by the bow-shaped line, while the lung shadows remain entirely above this line and are not visible through the "stomach-bubble."

While all of these facts together may make the diagnosis almost positive, none is pathognomonic. The diagnosis rests on the phenomena exhibited by the patient as a whole. 


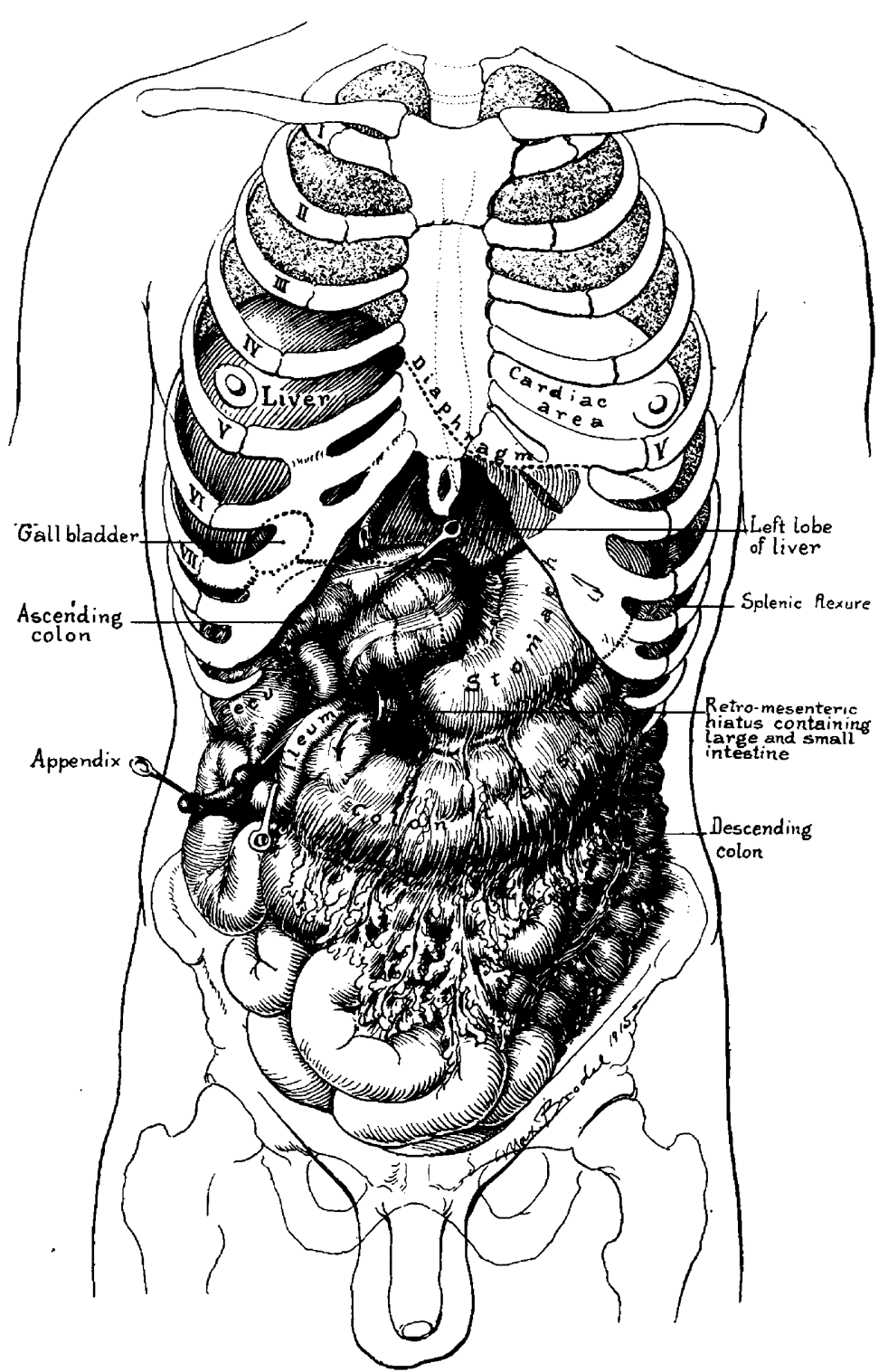

Fig. 3.-Diagram by Max Brödel from sketch at operation. This shows the high-position and eventration of the right side of the diaphragm; the mesenteric anomaly and its hernia; and the malposition of the cecum and ascending colon. 
The tendency is to exclude paralysis of the diaphragm, with consequent loss of tone and high position, from the category of eventration. These cases are usually fatal or improve before the typical clinical and anatomical picture of eventration is produced. Important in this connection is the study of the electrical condition of the phrenic rerves by Jamin's method of faradization of the phrenics in the neck. During the stimulation of the nerve, movements of the diaphragm may be observed by fluoroscopy. By this means, the presence or absence of degeneration of the nerve can be determined, and also an estimate of the muscular condition of the diaphragm can be made. These, however, are the limits of the conclusions to be drawn from such observations, and the method cannot be used to differentiate definitely between hernia and eventration.

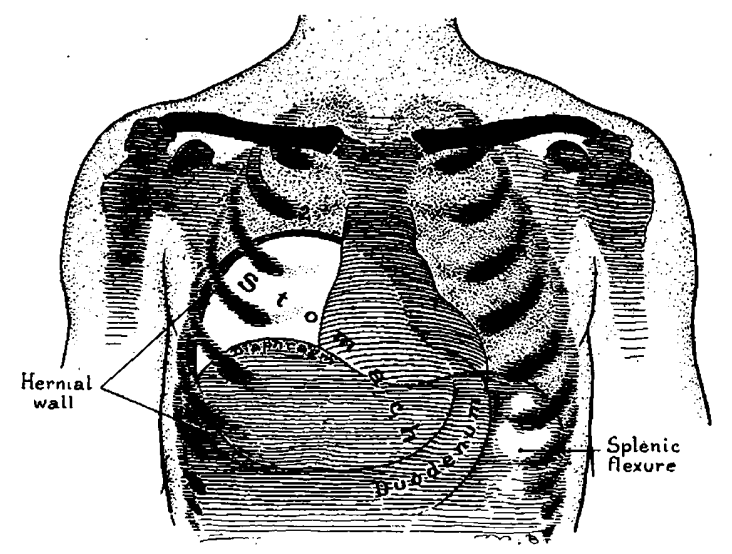

Fig. 4.-Schematic copy of roentgenogram published by Dietlen and Knierim to illustrate Roentgen-ray findings in hernia of the right side of the diaphragm. Here the clear stomach region lies between shadows of the lung above and the liver below. In eventration of the right diaphragm the liver shadow lies between the lung shadow and a bright area due to distended colon in the lower left chest.

\section{PATHOLOGICAL ANATOMY}

The pathological anatomy of the diaphragm has been studied at necropsy or operation in twenty-two cases of eventration. In all instances, whether the affection has occurred on the right or the left side, the diaphragm has been found to be a thin, translucent membrane. The peritoneal and pleural reflections have covered the sides of the diseased organs smoothly and uniformly. Between these membranes there has always been found a layer of fibrous tissue, which in some cases contained a few strands of muscle tissue and in others consisted of only a "thin aponeurotic sheet." In the case reported by Doering there was a fringe of normal muscle around the parietal attachments of the diaphragm, disappearing as the dome was reached. In Benda's 
case the affected half of the diaphragm was distinguished by its opaque whitish color from the red, muscular aspect of the healthy side. Benda found that the strands of muscle fibers were replaced by parallel bands of fat cells, and he termed the process "lipomatous pseudohypertrophy," correlating it with one of the forms of myogenic muscular atrophy. The pathological anatomy of structures closely related to the diaphragm is variable. The phrenic nerves have been examined in a number of cases of eventration. As in Benda's study, they have been found to be reduced in size in comparison with the nerve of the healthy side, but have been composed of normal fibers, with no great evidence of degeneration in the nerve trunk or its nuclei. The pleura, peritoneum and blood supply of the diaphragm have not shown any abnormalities, and the attachments of the diaphragm have been normal. The lungs and abdominal viscera, however, have exhibited various developmental anomalies, which will be considered when the etiology of the condition is discussed. A significant fact, revealed at autopsy, is that while the diaphragm may be ballooned upward by the abdominal organs, the lungs are not compressed. The heart and mediastinum may be displaced to the right, or left. In fact, displacement of the heart to the right, simulating dextrocardia, is the invariable accompaniment of eventration of the left side of the diaphragm.

\section{ETIOLOGY}

When Cruveilhier established the category of eventration of the diaphragm, he regarded the condition as an acquired lesion. Thoma, on the other hand, published the hypothesis that the condition is a congenital anomaly of development. Since then, evidence in favor of each opinion has been adduced, but the majority of the authors, as shown in Table 2, have supported the hypothesis of the congenital origin.

In favor of the acquired nature of the disease, cases have been cited in which the condition has been apparently secondary to (1) pressure differences on the two sides of the diaphragm, (2) disease of the muscle, and (3) disease of the nerves. All of these may follow trauma, but each class embraces several specific diseases. It has been demonstrated that elevation of the dome of the diaphragm follows increased abdominal pressure. The chief states producing this are pregnancy, ascites, and chronic gastro-intestinal distention, such as meteorism and Hirschsprung's disease. If this factor of increased pressure in the abdomen bore an important etiological relationship to eventration, the frequency of pregnancy in general-and sometimes iri the individual-should find a counterpart in a large number of women suffering from eventration of the diaphragm. Table 2, how- 
ever, shows a surprising minimum of females among those presenting this affection. Among the other dynamic intra-abdominal causes of eventration, great importance has been attached by Hoffmann to chronic gaseous distention of the intestines in his hypothesis that "chronische Magenblase" produces at least "rudimentary eventration." His conception is that pressure on the diaphragm produces circulatory disturbances which lead to "loss of elasticity," degeneration of the muscle, and stretching of the organ. While it is conceded that "high position" may be produced in this way, it is doubtful whether the condition found in eventration actually results from this process. A strongly unfavorable criticism of this hypothesis is that bulging of the abdominal wall and ptosis of the viscera are the most common sequels of increased abdominal pressure, while in eventration, the tonus of the abdominal wall is at least normal. From the pulmonary side, retracting pleural adhesions may drag the dome of the diaphragm upward. Thoma describes a case in which this occurred, but he uses it as a contrast to true eventration, from which category he eliminates it, along with similar cases of mechanical "hochstand" of the diaphragm.

The question of the etiological significance of disease of the muscle and nerves in eventration of the diaphragm is more difficult to settle. It is well known that in progressive muscular atrophy, the diaphragm becomes so degenerated and weakened that its loss of function may be the cause of death. But here, while the state of the diaphragm may resemble that seen in some cases of eventration, its evident part in a general disease differentiates it from the localized diaphragmatic lesion of eventration. In Benda's case, for example, although there was a "lipomatous pseudohypertrophy" of the atrophied muscle, there was no accompanying nerve lesion. Peripheral neuritis of the phrenic nerve, after diphtheria and other infectious diseases, and in toxic states like alcoholism and beriberi, has produced relaxation of the diaphragm and consequent high position. In practically all of these cases, however, the normal tone and position of the diaphragm has been regained when the nerve lesion improved (Behrenroth), or if death has occurred, the diaphragm has not shown the flaccid fibrosie characteristic of eventration.

The criteria of the congenital origin of eventration, as noted by Thoma in 1882, have gained validity from the studies of subsequent investigators. These points are chiefly: (1) the coincidence of the frequency of eventration of the left side of the diaphragm with the complexity of the development of that side of the organ, (2) the occurrence of eventration in the fetus and the new-born, (3) its association with other congenital anomalies of the body, and (4) the usual absence of symptoms over long periods of time. Detailed 
recapitulation of the embryology of the diaphragm would be more confusing than useful here, where all that need be emphasized is that the left side of the organ develops from a number of sources and is not entirely formed until some time after the completion of the relatively simple development of the right side. On the right, the liver, growing in the septum transversum, which early separates the pleural and peritoneal cavities on that side, seems to guard the right side of the diaphragm from developmental disturbances. The left side, however, grows in close association with the left lobe of the liver, the stomach and spleen, the pericardial formation, one of the pulmonary ridges, and the pleuroperitoneal membrane. In addition, the posterior portion of the left side of the diaphragm is the last to close. This undoubtedly accounts for the great predominance of congenital hernia of the left side of the diaphragm. By analogy, the great relative frequency of eventration of the left side suggests not only that this condition is associated with the developmental intricacy of that side, but also that it is a congenital abnormality. The finding of eventration in either fetuses or young children in four of the forty-five cases of the disease is good evidence in favor of its congenital origin (see Cases 1, 3, 25,35 in Table 2). In nine cases (Cases 8, 10, 12, 13, 15, 16, 40, 45, Table 2), other abnormalities of the lungs or abdominal viscera were present. These were abnormally lobulated lungs, "stunted lungs," congenital hernias, and true dextrocardia. In the case described in this paper, the deformity of the mesentery and the position of the cecum under the right costal margin were clearly congenital abnormalities. This coincidence of rare anomalies suggests a common etiological relationship; namely, that eventration also is a congenital dystrophy. In connection with recent studies of body growth, Byloff has published papers on the thesis of high position of the diaphragm as a stigma or degeneration. He found moderate high position in a number of individuals who showed defective development of various organs and parts of the body. None of Byloff's examples is a case of eventration, but his work is capable of interpretation in favor of the congenital origin of this affection.

It has been noted, in the discussion of the pathological anatomy of eventration, that the lung lying above the distended diaphragm has not been compressed, although its thoracic chamber has been always greatly reduced. This uniform absence of compression of the contiguous lung is to be emphasized here as one of the strongest arguments in favor of the congenital origin of eventration of the diaphragm.

\section{PROGNOSIS}

It is probable that if the degree of eventration be extreme in the new-born, this condition is incompatible with life. After the first year, however, the disease is rarely a cause of death. While the 
greatest number of cases have been found in individuals between the ages of 20 and 50 years, instances have been observed in patients in the eighth decade of life. Cardiorespiratory diseases have not been unusually frequent in those suffering with eventration of the diaphragm, but gastro-intestinal symptoms have been the most distressing feature. The danger of incarceration of the displaced abdominal viscera is the only element which renders the prognosis grave.

\section{SUMMARY}

This paper reports a case of eventration of the right side of the diaphragm. This diagnosis, made from physical examination, is the frst of its kind determined during the life of the patient. The clinical impression was confirmed at an operation.

Tabulation is made of forty-five cases of eventration of the draphragm. Of these, three were right-sided, while forty-two were left-sided lesions.

In the differential diagnosis between eventration and allied states, the difficulties are pointed out, particularly with regard to the differentiation from hernia of the diaphragm. No single method is capable of establishing this differentiation, but all together render the diagnosis reasonably certain.

The various etiological hypotheses are summarized, showing that the weight of evidence is in favor of the opinion that the disease has a congenital origin.

\section{REFERENCES}

Appel, F.: Zur Kenntnis der Eventratio diaphragmatica, Inaug.-Dissert. Greifswald, 1911.

Arnsperger, H.: Deutsch. Arch. f. klin. Med., 1908, xciii, 88.

Baetge, P.: Deutsch. Arch. f. klin. Med., 1913, cx, 49.

Becker, T.: Fortschr. a. d. Geb. d. Röntgenstrahlen, 1911, xvii, 183.

Behrenroth, E.: Samml. klin. Vortr., 1911, No. 642, Inn. Med. No. 205.

Beltz: München. med. Wchnschr., 1910, lvii, 1006.

Bergmann, J.: Ergeb. d. inn. Med. u. Kndheilk., 1913, xii, 327.

Byloff, K. : Ztschr. f. angew. Anat. u. Konstitutionslehre, 1913, i, 176.

Crispino, M.: Riforma med., 1900, iii, 436, 447, 459.

Cruveilhier: Traité d'Anatomie pathologique générale, 1849, ii, 617 (Paris).

Dietlen, H., and Knierim, G.: Berl. klin. Wchnschr., 1910, xlvii, 1174.

Doering, H.: Deutsch. Arch. f. klin. Med., 1902, 1xxii, 407.

Eggeling, H.: München. med. Wchnschr., 1912, 1xix, 2284.

Eppinger, H.: Allg. u. spez. Pathol. d. Zwerchfells, Suppl. Nothnagel's spez. Path. u. Therap., Wien, 1911.

Fischer, H.: Med. Rec., New York, 1914, 1xxxvi, 653.

Fraenkel, A.: Deutsch. med. Wchnschr., 1902, xxviii, V, 343.

Franck, O.: Beitr. z. klin. Chir., 1911, 1xxiv, 358.

Froriep: Kleiner's Repertorium, 1837. Cited by Lacher, Deutsch. Arch. f. klin. Med, 1880, xxvii, 268.

Glaser, F.: Deutsch. Arch. f. klin. Med., 1903, 1xxviii, 370.

Griffin, H. Z.: Ann. Surg., 1912, lv, 388.

Haase, H.: Wien. klin. Wchnschr., 1913, xvi, 193. 
Herz, A.: Wien. klin. Wchnschr., 1907, xx, 1463.

Hildebrand, H., and Hess, O.: München. med. Wchnschr., 1905, lii, 745.

Hoffmann, F. A.: München. med. Wchnschr., 1907, liv, 112.

Jamin, Festschrift f. J. Rosenthal, 1906, ii, 85.

Kayser, K.: Fortschr. a. d. Geb. d. Röntgenstrahlen, 1913, xx, 240.

Kienböck, R.: Ztschr. f. klin. Med., 1907, lxii, 321.

Kienböck, R.: Wien. klin. Wchnschr., 1898, xi, 539.

Königer, H.: München. med. Wchnschr., 1909, 1vi, 282.

Krause, P.: Deutsch. Ztschr. f. Nervenh., 1913, xlvii, 328.

Laennec, R. T. H.: L'Auscultation Médiate, Paris, 1829, ii, 450.

Lawrence: Lancet, London, 1852, ii, 212.

Lotze, K.: Deutsch. med. Wchnschr., 1906, xxxii, 1622.

Von Malkow: Russk. Vrach., 1912, 1i. Cited by Bergmann.

Manges, M., and Wessler, H.: Med. Rec., New York, 1914, 1xxxvi, 134.

Marsh, F. H.: Lancet, London, 1867, xlviii, 298.

Meckel: Cited by Zwanziger, Inaug.-Dissert., Halle, 1819.

Neisser, E.: Ztschr. f. klin. Med., 1901, xlii, 88.

Otten, M., and Schefold: Deutsch. Arch. f. klin. Med., 1910, xcix, 468.

Petit, J. L.: Traité des maladies chirurgicales, 1790, iv, 234.

Pyl, J. T.: Aüfsatze u. Beobacht. a. d. ger. Med., 1784, Series 5, p. 29.

Reuss: Deutsch. med. Wchnschr., 1913, xxxix, 743.

Risel, W.: München. med. Wchnschr., 1907, liv, 637.

Sailer, J., and Rhein, R. D.: Am. Jour. Med., Sc., 1905, cxxix, 688.

Scheidemandel, E.: München. med. Wchnschr., 1912, lix, 2168.

Schlippe, P.: Deutsch. Arch. f. klin. Med., 1903, lxxvi, 450.

Scholz, L.: Berl. klin. Wchnschr., 1911, xlviii, 339.

Struppler, T.: Deutsch. Arch. f. klin. Med., 1901, 1xx, 1.

Tennant, J.: Edinburgh Med. Jour., 1894, x1, 29.

Thoma, R.: Virchow's Arch., 1882, 1xxxviii, 515.

Wieting: Deutsch. Ztschr. f. Chir., 1906, 1xxxii, 314. 